\title{
DUMP BUSTER - A REVIEW
}

\author{
Nishant Kumar Pandey \\ SCSE, B.Tech $3^{\text {rd }}$ year \\ Galgotias University \\ Greater Noida, UP, India
}

\author{
Nishant Sinha \\ SCSE, B.Tech $3^{\text {rd }}$ year \\ Galgotias University \\ Greater Noida, UP, India
}

\author{
Anjani Kumar Singh \\ SCSE, B.Tech $3^{\text {rd }}$ year \\ Galgotias University \\ Greater Noida, UP, India
}

\begin{abstract}
This application is made in the view to support the cleanliness drive of India. According to the EPI (Environmental Protection Index) 2018, India ranks among the bottom five nations in terms of environmental health. A world bank report in 2006 mentioned that India loses $6.4 \%$ of its GDP every year because of issues related to sanitation and environmental protection. 'Dump Buster' will help people in tackling the issue of cleaning out garbage piles. For this application, we used some tools to detect the piles of garbage by accessing the camera for real-time detection. However, there are some protocols that users must follow, i.e., see piles of garbage and capture it real-time by the camera and after that informing to the Cleanliness Authority. In this application, the User Interface is eco-friendly which gives you the motivation to do cleanliness movement. In which, we are giving you the authority to send the waste detected picture along with the real-time address to the authority. After that, the notification is shown in the app that the complaint has been successfully resolved. We are designed this app in every language according to user preference they will use. For detecting the piles of garbage, we used the machine learning approach that helps to detect the piles of garbage. The picture should be recognizable otherwise the machine learning model doesn't examine the wastes. We made a huge database or dataset for detecting purpose in which we distribute every single pile in a folder that makes more comfortable to the model to detect garbage piles. "Dump Buster" will help to manage the situation of cleaning wastages in India.
\end{abstract}

Keywords - Waste Detection, Cleanliness Drive, Waste Segregation.

\section{INTRODUCTION}

Nowadays the Machine Learning and Artificial Intelligence are developed enough that is the ability to programming Auto driving mode, Human Interactions, and, etc. These features are having high benchmarks in the technical industry. Machine Learning is the only approach that improves itself through experience and also by the use of data. Now, it is not a person who only learns to drive cars and tries to understand machine learning approaches but a machine or a car will drive the car because of machine learning and artificial intelligence.
The "Dump Buster" application allows the user to click the photo in real-time of a garbage pile. The picture is then run through a machine learning model to make the validation that it is a garbage pile. The image is thereafter sent to the authorities in the locality along with the location of the pile. The authorities can then tackle the issue and then mark it as cleared, after which the complainant will get a notification that the complaint has been resolved.

\section{SUBSECTION}

(A) Contains Literature Review/ Comparative Research introduced brief details regarding the designing and designing of the application.

(B) Provides detailed information on the required tools.

(C) Data about the related work.

(D) Offers the proposed work plan.

(E) Contains the approach that is used for the project.

\section{A. Literature Review/Comparative Study -}

There are several projects which work on image processing. The "Automated Domestic Waste Segregator" was a project that was based on image processing in which it consists of both hardware and software components that helps to do sorting of waste at the domestic level. They aimed to separate the waste efficiently on the domestic level so that it would help to authority to separate them on a large scale. This project was fully focused on helping in the easy recovery of useful and recyclable products.

In India, all the garbage is mostly disposed of rather than in other countries. One more project was focusing on waste classification. The name of the project is "Waste Classification System using Image Processing" published in May 2019, for the classification of plastics waste using convolution neural networks. In the whole world, the biggest problem is to maintain the environment clean but it is a big challenge to every country to segregate renewable waste. They had a vision and plan for how they were going to segregate the plastic wastes and they did it.

"Automated Waste Segregation System using IoT", their aim has to reduce cost, optimizing the resources. From this, they were trying to reduce traffic due to garbage on road. 


\section{International Journal of Engineering Applied Sciences and Technology, 2021 \\ Vol. 5, Issue 12, ISSN No. 2455-2143, Pages 122-125 \\ Published Online April 2021 in IJEAST (http://www.ijeast.com)}

"Dump Buster" is an application that also focuses on waste management to make an eco-friendly environment which would help in maintaining good climate conditions. The aim to make this app is to clean our India and deals with the sorting of the wastes into different categories. "Dump Buster" is also a cost-efficient product. "Dump Buster", made for android users and the machine learning model, we use SVM algorithm to train it and also pre-process the image in realtime.

Some non-profit organizations are working in the sector of waste segregation or waste management like "Saahas".

\section{B. Required Tools -}

- Hardware:

- Software:

○ Smart Phones (Android)

○ Proper Functioning Camera

$$
\begin{array}{ll}
\circ & \text { Android } 5.0 \text { or more } \\
\circ & \text { GPS }
\end{array}
$$

\section{Background and Related Work-}

Machine learning is a teacher for computers that teaches to do what comes naturally to humans and animals learn from experiences. Machine learning models use some computational methods that help them to "learn" info directly from data without relying on a predetermined equation as a model.

\section{Related Work-}

Every Creator of smart waste segregation uses their methods and techniques for development. The Waste Segregation using image processing team are the first risk-taker who deals with this issue but in a different mindset. They made a sensor that senses the garbage and separates them based on their categories. The feature of waste detection or segregation is to classify the waste and separate them. The model always goes through the learning process to become the best detection model. The key point is to make the cleanest India ever.

\section{Proposed plan of work-}

The task began by seeing any garbage piles on any street via users. This can be anything only they need to open the application and click the picture of that garbage pile. The user must on the internet for sending purposes. The picture, clicked by the user send to the machine learning model in real-time for preprocessing and detecting the garbage piles. After the detection process is done by the machine learning model, the processed image and the address is sent to the cleaning authority. Cleaning Authority quickly acknowledges the image and the given address and tackles the issue. After all the cleaning processes, cleared notification regarding successful cleaning is shown in the application notification panel.

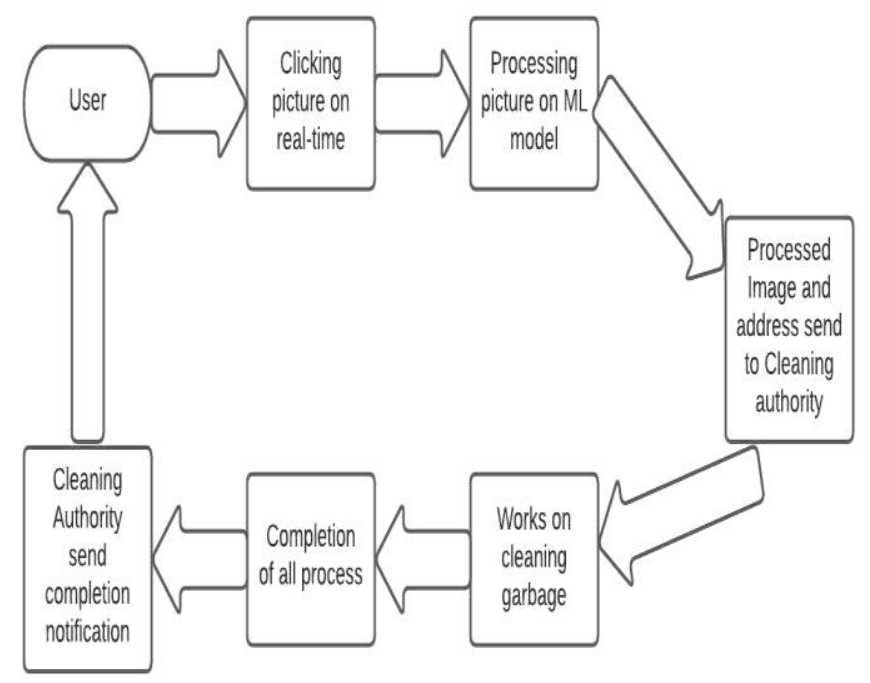

Fig.1. Basic Workflow

Figure 1 shows how to basic dump buster process. Image Processing is used to process digital pictures through an algorithm. This processed picture is sent to the cleaning authority by clicking the place address. Sometimes, the picture may not be understood but by the given address they do start cleaning. Because of network or server, you may suffer from detection or sending problems but rather than you won't suffer from any other issue. The next stage is to show the completion is done through notification. After completion, the green color is shown in the notification panel.

\section{E. Working Methodology-}

The creator should create first is a set of a dataset of different types of waste materials. All the features for the datasets are detected using Extraction Algorithms. All the detected features are stored in a bag of a variable. Now, we use SVM to trained the variable in Matlab. Once the training is accomplished, the prediction is given by the stored output variable. Start the application, open the camera section to run live dump detection, and get the image. Predicting dump using the extracted features by comparing to the stored output variable and plot the result. The stored picture is sent to the authority and they tackle the situation and mark it cleared, after that the complainant will get a notification that the complaint has been resolved or completed. 
International Journal of Engineering Applied Sciences and Technology, 2021

Vol. 5, Issue 12, ISSN No. 2455-2143, Pages 122-125

Published Online April 2021 in IJEAST (http://www.ijeast.com)

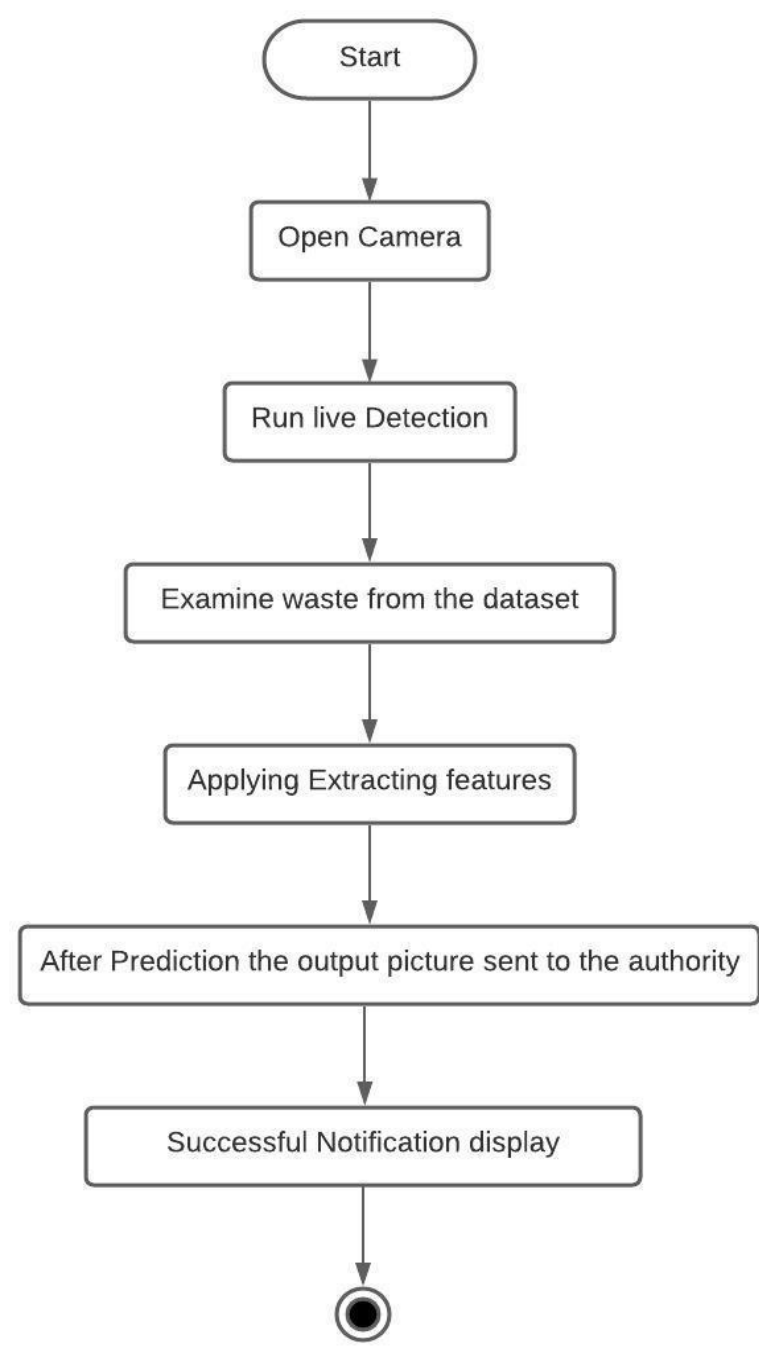

Fig.2. Working Diagram

This application design is aim to detect the pile of garbage using the features that are:

- The dataset contains:
○ Plastic waste
o Paper waste
- Metallic Waste
- Vegetable Waste
- Glass Waste
- Biodegradable or Non-Biodegradable wastes

- Analyzing the picture through the given dataset.

- Produce the preprocessed picture.

- After training the output picture and the address sent to the authority.

- Authority does their cleaning work.

- Complaint resolving notification shows on the notification panel of the complainant.

\section{F. Merits of Proposed Work-}

- Start camera.

- run-live detection of waste.

- Applying extraction feature algorithm.

- Predict the waste output by comparing the extraction feature with the output variable.

- The output image is sent to the authority.

- Authority accepts the complaint and processes it by using the given provided address.

- The complainant will get a notification that the complaint has been completely resolved.

\section{G. Architecture Diagram-}

Here, we explain the whole working through architecture digram. The Process and the approaches that we implement in our project.

The Steps to explain the architecture part:

- The User has to open the camera first.

- Clicking the real-time picture for run live detection.

- With the help of a dataset, we can able to inspecting the waste.

- After the recognition is positive then the picture with detecting wastes shows in your display.

- The scanned picture and the address where the picture clicked, send to the cleanliness authority.

- After the pile of waste is taken away then the successful notification displays.

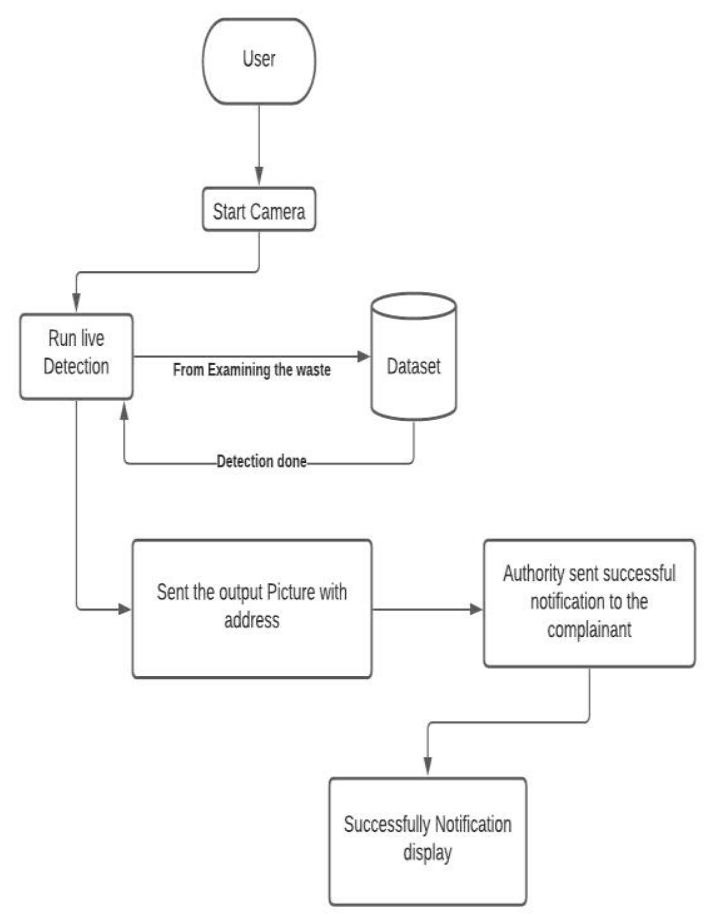

Fig.3. Architecture Diagram 


\section{ACKNOWLEDGEMENT}

We are thankful to our guide P. Rajakumar for his support and guidance throughout the project. I would also thank the SCSE department of Galgotias University for their support of the innovations and for providing a research-friendly environment.

\section{REFERENCES}

[1] Researchgate.com

[2] https://en.wikipedia.org/wiki/Environmental_issues_in_In dia

[3] https://en.wikipedia.org/wiki/Swachh_Bharat_Mission

[4] Jahangiri, Arash. (2015). Applying Machine Learning Techniques to Transportation Mode Recognition Using Mobile Phone Sensor Data. IEEE Transactions on Intelligent Transportation Systems.

[5] Machine Learning, Tom Mitchell, McGraw Hill, 1997.

[6] Neftci, Emre O., and Bruno B. Averbeck. "Reinforcement learning in artificial and biological systems." Nature Machine Intelligence 1.3 (2019): 133-143.

[7] Chinnathurai, Balaji Masanamuthu, Ramkrishna Sivakumar, Sushuruth Sadagopan, and James M. Conrad. "Design and implementation of a semi-autonomous waste segregation robot." In SoutheastCon 2016, pp. 1-6. IEEE, 2016.

[8] J Sanjai, V Balaji, K K Pranav, B. Aravindan (2019), "Automated Domestic Waste Segragator Using Image Processing", International Research Journal of Engineering and Technology (IRJET).

[9] https://www.irjet.net/archives/V6/i4/IRJET-V6I479

[10] https://www.dezyre.com/article/top-10-machine-learningprojects-for-beginners-in-2021/397

[11] Sharanya.A, U.Harika, N.Sriya, Sreeja Kochuvila (2017), "Automatic Waste Segregator", IEEE Journal.

[12] Rifath Jahan, M.G. Jhansi Rani, U.L.N. Manasa, G. Susmitha, P. Nikitha, M.K. Girija (2020), "Automated Waste Segregation System Using IoT", International Research Journal of Engineering and Technology (IRJET). 